\title{
Effects of Voltage Gradients on Electro-Osmotic Characteristics of Taizhou Soft Clay
}

\author{
Shen Yang ${ }^{1,2, *}$, Feng Jianting ${ }^{1,2}$, Shi Wen ${ }^{1,2}$, Qiu Chenchen ${ }^{1,2}$ \\ ${ }^{1}$ Key Laboratory of Geomechanics and Embankment Engineering of Ministry of Education, Hohai \\ University, Nanjing, 210098, P. R. China. \\ ${ }^{2}$ Jiangsu Research Center for Geotechnical Engineering Technology, Hohai University, Nanjing, \\ 210098, P. R. China. \\ *E-mail: shenyang1998@163.com
}

doi: $10.20964 / 2019.03 .06$

Received: 1 November 2018 / Accepted: 7 January 2019 / Published: 7 February 2019

To study the electro-osmotic characteristics of Taizhou soft clay under different voltage gradients, a series of laboratory electro-osmotic experiments with different voltage gradients were conducted. The electro-osmotic treatment effects of these tests were compared by monitoring the drainage, current, voltage, soil element mass fraction and soil structure. The electro-osmotic method was further studied from a theoretical perspective based on the inherent link between macro-level and micro-level indexes. The results showed that the drainage was effectively improved with an increasing voltage gradient when the voltage gradient was within the range of $1 \mathrm{~V} / \mathrm{cm} \sim 2 \mathrm{~V} / \mathrm{cm}$, but no significant improvement was observed when the voltage gradient was further increased. Although an excessively high voltage gradient increased the drainage, it also led to greater energy consumption per unit volume of drainage. An increased voltage gradient improved only the proportion of the effective voltage in the early stage of the electro-osmotic process; from a long-term perspective, an excessively high voltage gradient was not useful for increasing the ratio of the effective voltage to the output voltage. $\mathrm{Na}^{+}$was the main active ion in Taizhou soft clay during the electro-osmotic process and was the key factor that affected the drainage and drainage velocity. When the voltage gradient was within the range of $1 \mathrm{~V} / \mathrm{cm} \sim 2 \mathrm{~V} / \mathrm{cm}$, the concentration of migratory $\mathrm{Na}^{+}$increased with an increasing voltage gradient, but no significant improvement was detected when the gradient was further increased. The structure of Taizhou soft clay changed from flocculent to granular after electro-osmotic treatment when the voltage gradient was within the range of $1 \mathrm{~V} / \mathrm{cm} \sim 1.5 \mathrm{~V} / \mathrm{cm}$ and from flocculent to schistose after electro-osmotic treatment when the voltage gradient was within the range of $1.75 \mathrm{~V} / \mathrm{cm} \sim 2.25 \mathrm{~V} / \mathrm{cm}$. Finally, based on the inherent link between the macro and micro levels, a new one-dimensional electro-osmotic consolidation equation that can accurately forecast changes in the excess pore water pressure during electro-osmotic treatment was deduced considering variations in the effective voltage.

Keywords: Voltage gradients; Electrochemical problem; Microscopic active ion; Soil structure; New one-dimensional electro-osmotic consolidation equation. 


\section{FULL TEXT}

(C) 2019 The Authors. Published by ESG (www.electrochemsci.org). This article is an open access article distributed under the terms and conditions of the Creative Commons Attribution license (http://creativecommons.org/licenses/by/4.0/). 